\title{
Information Articles
}

\section{The International Symposium on Nanoparticle Technology in memory of late Mr.Masuo Hosokawa}

The International Symposium on Nanoparticle Technology was held in memory of late Mr.Masuo Hosokawa at the Imperial Hotel Osaka, Japan on Tuesday, April 24, 2012. It was organized by Hosokawa Powder Technology Foundation with the Sponsorship of Hosokawa Micron Corporation as one of special events of the Foundation. About 120 people from the industries and academic organizations attended this symposium and had many discussions. On this occasion, the publication of the 2nd edition of the Nanoparticle Technology Handbook was announced and some copies of it were displayed in the conference hall of the symposium.

Session 1 Chaired by Prof.Yutaka Tsuji (Emeritus Prof.of Osaka Univ.)

\section{Lecture 1}

- "Particle Advances for Nano and Bio Technology Applications"

Lecture 2

- "Manufacture of Functional Ceramic Nanopowders by Thermal Decomposition of Metal-Gel Structures"

\section{Lecture 3}

- "Trend of Nanoparticle Technology in ASEAN with Emphasis on Thailand"

Session 2 Chaired by Prof.Makio Naito (Osaka Univ.)

Lecture 4

- "Process Technologies for Ultrafine Particles - from Research to Production"

\section{Lecture 5}

- "From Bulk Solids Blending into Fine Particle Engineering”

\section{Lecture 6}

- "Creation and Application of Nanoparticles for Advanced Functional Materials"

- Closing speech
Prof.Brij M.Moudgil

(Univ.of Florida, USA)

Prof.Mojtaba Ghadiri

(Univ.of Leeds, UK)

Prof.Wiwut Tanthapanichakoon, Emeritus Prof.of Chulalongkorn Univ., Thailand, Prof.of Tokyo Institute of Technology, Japan

Dr.Jürgen Stein

(Hosokawa Alpine AG)

Dr.Peter van der Wel

(Hosokawa Mcron BV)

Dr.Toyokazu Yokoyama

(Hosokawa Micron Corporation.)

Mr.Kiyomi Miyata

(President of Hosokawa Micron Corporation)

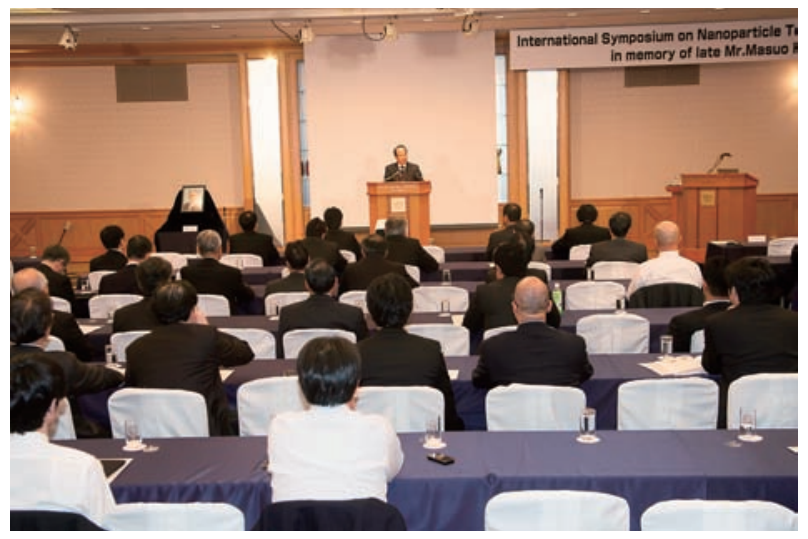

Closing remarks by Mr.Miyata, President of Hosokawa Micron Corporation

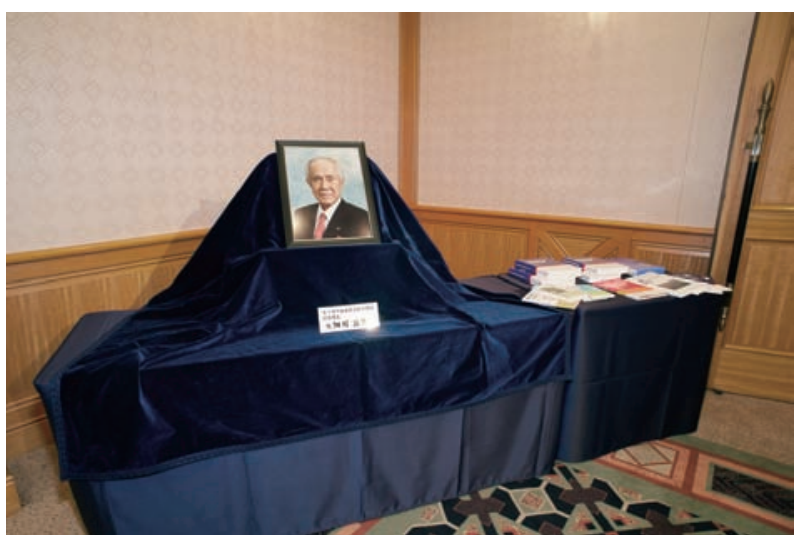

Display of portrait of late Mr.Masuo Hosokawa and the 2nd edition of Nanoparticle Technology Handbook 